\title{
THORACOSCOPIC EXCISION OF PRENATAL DIAGNOSED EXTRALOBAR PULMONARY SEQUESTRATION - CASE REPORT
}

\author{
Vlad Laurentiu David ${ }^{1,2}$, Diana Popescu ${ }^{2}$, Razvan Nitu ${ }^{3}$, Bogdan Ciornei ${ }^{1,2}$, Aurelia Sosoi ${ }^{2}$, Marius \\ Calin Popoiu ${ }^{1,2}$, Eugen Sorin Boia ${ }^{1,2}$
}

\section{Abstract}

Background: Pulmonary sequestrations are rare congenital bronchopulmonary malformation. Two types of bronchopulmonary sequestration have been described: intralobar and, extralobar sequestration. Case report: We present the case of a male patient with extralobar sequestration diagnosed prenatally and successfully treated by means of video-assisted surgical excision at the age of 7 months. Prenatal diagnostic of pulmonary malformation was suspected at routine ultrasound and confirmed on fetal MRI. The baby was delivered at 39 weeks of gestation by $\mathrm{C}$-section. The diagnostic of extralobar sequestration was confirmed by CT scan performed at the age of 1 month. The child was asymptomatic so the surgical excision of the mass was performed after the age of 6 months by means of video-assisted thoracoscopy. The procedure was technical challenging but underwent flawless. The postoperative course was uneventful. Conclusions: Prenatal diagnostics is a very useful tool in planning and making appropriate therapeutic decision for patients with pulmonary sequestration. Video-assisted thoracoscopic excision is the optimal treatment option for extralobar sequestration.

Keywords: extralobar sequestration, pulmonary malformation, prenatal diagnostic, surgical excision, thoracoscopy

\section{Introduction}

Pulmonary sequestrations are rare congenital bronchopulmonary malformation. They consists of a mass of non-functioning pulmonary tissue that has no connection to the tracheobronchial tree [1]. Two types of bronchopulmonary sequestration have been described: intralobar sequestration (ILS), the non-functioning pulmonary mass is located within a pulmonary lobe, surrounded by normal pulmonary parenchyma and, extralobar sequestration (ELS) where the malformation is usually located inside the pleura as a distinct mass covered by its own pleura [2]. ELS can be found at any level in the pleural space and in rare instances it can be found within or beneath the diaphragm [3].

The major feature of pulmonary sequestrations is that the blood supply derived from the systemic circulation [2]. The arterial supply, most commonly emerges from the thoracic aorta $(73 \%)$, the cranial portion of the abdominal aorta, celiac trunk, splenic artery, as well as intercostal arteries. The pathogenesis is related to abnormal budding of the lungs and, if the abnormal bud arises before the development of the pleura, it is invested with the adjacent lung and becomes an ILS. ELS develops after visceral pleural formation, it grows separately and acquires its own pleural covering [3].

ELS may be asymptomatic or may produce mass effect related symptoms or complications [2, 3]. In the past many ELS were incidentally diagnosed during a plain Xray. Nowadays most of the bronchopulmonary malformations are detected prenatally, which offers better planning for the management and early treatment options [4]. Management options include non-operative treatment, surgical excision or endovascular treatment $[5,6,7]$

We present the case of a male patient with ELS diagnosed prenatally that was successfully treated by means of video-assisted surgical excision.

\section{Case report}

On the routine ultrasound examination at 24 weeks gravida III para II pregnancy, a large mass was noticed inside the left pleural cavity of the fetus, replacing or compressing the normal pulmonary tissue. A fetal MRI was performed at 29 weeks and the images showed a cystic mass $37 / 35 \mathrm{~mm}$ large at the base of the left lung (Fig. 1). The images were suggestive for pulmonary malformation and based on the presence of the cystic images inside the mass, Congenital Cystic Adenomatoid Malformation (CCAM) was suspected. Further ultrasound monitoring was carried on and the pregnancy course was uneventful.

${ }^{1}$ Department of Pediatric Surgery and Orthopedics "Victor Babes" University of Medicine and Pharmacy Timisoara, Romania

${ }^{2}$ Department of Pediatric Surgery and Orthopedics “Louis Turcanu” Emergency Children's Hospital Timisoara, Romania ${ }^{3}$ Department of Obstetrics and Gynecology, Victor Babes" University of Medicine and Pharmacy Timisoara, Romania

E-mail: david.vlad@umft.ro,popescudia90@gmail.com,razvan.nitu@umft.ro, ciornei91@gmail.com, relysosoi@gmail.com, mcpopoiu@yahoo.com,boiaeugen@yahoo.com 


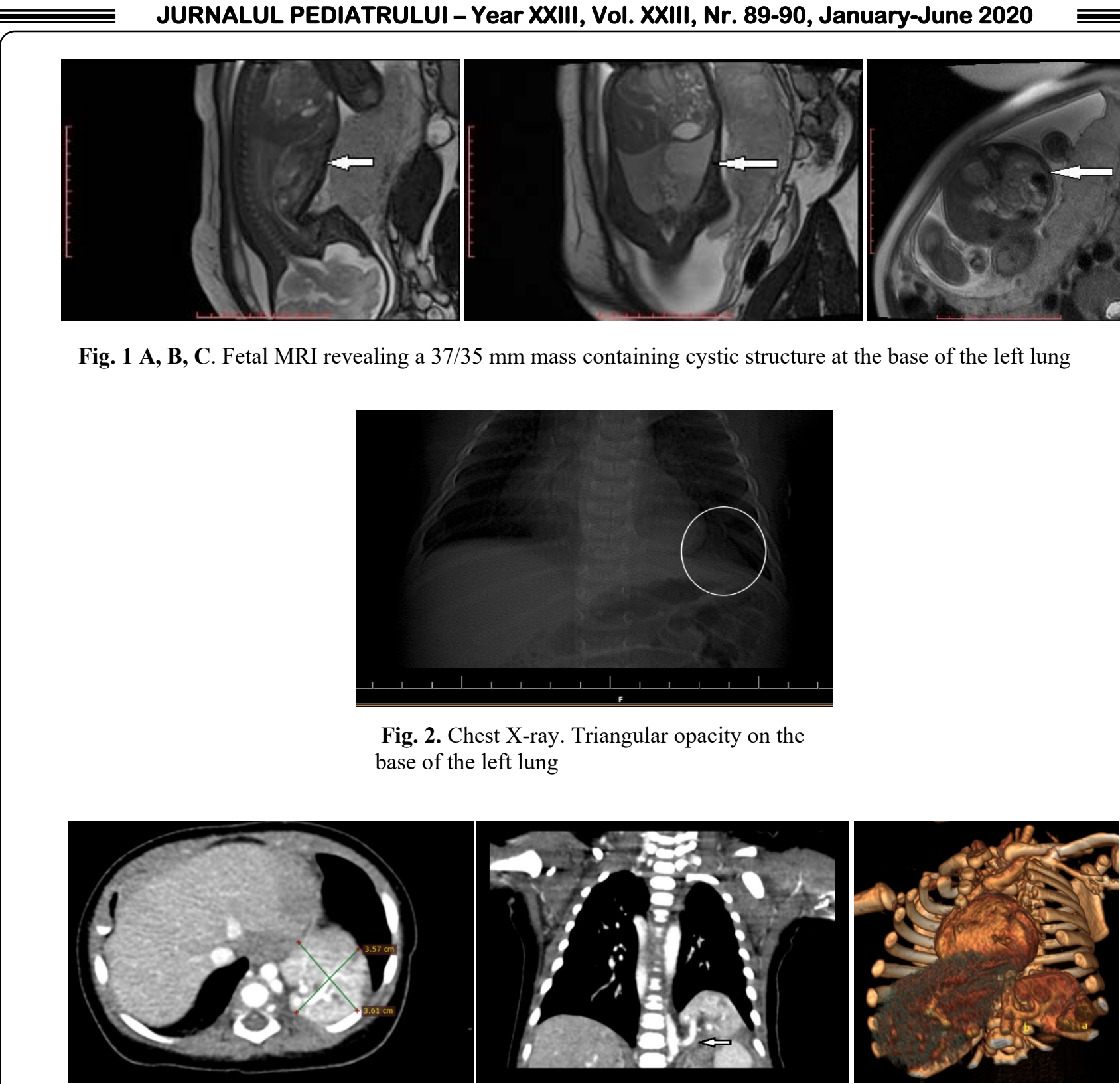

Fig. 3 A, B, C. Contrast enhanced thoracic CT scan with 3D reconstruction. Tumor is situated at the base of the left lung. Vascularisation from the descending aorta
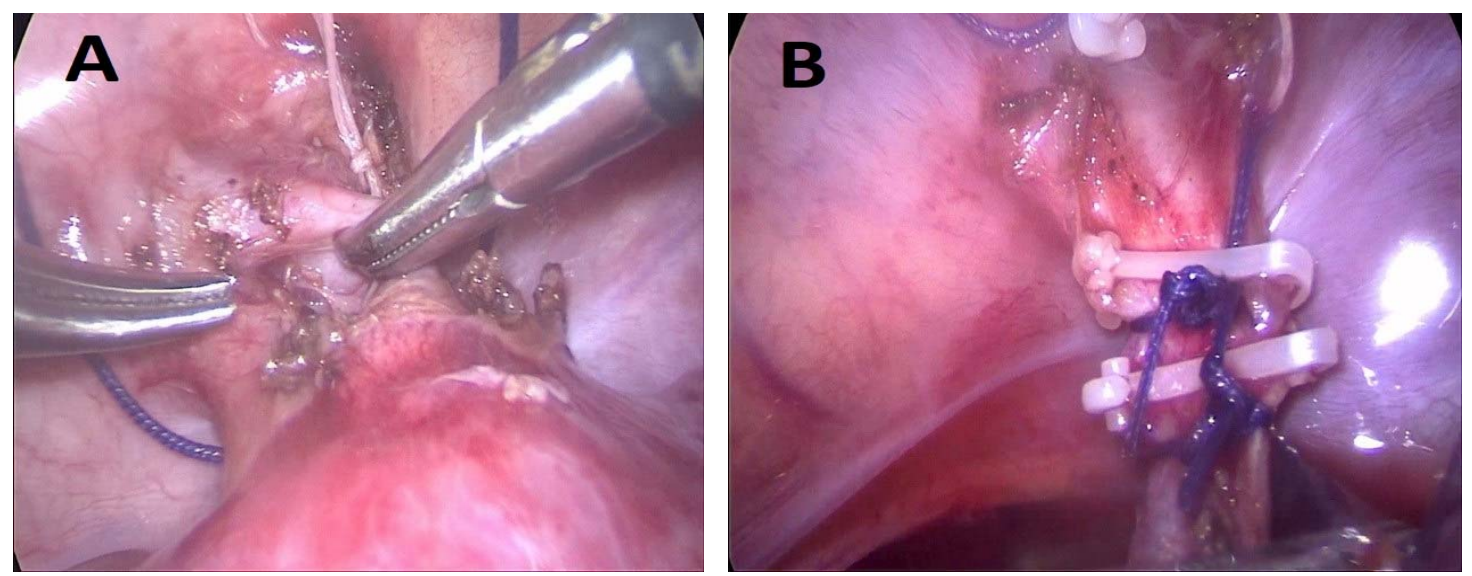

Fig.5 A) The blood supply: one artery that emerges from the descending aorta and a vein draining into the hemiazygos vein B) Vessels after ligation 


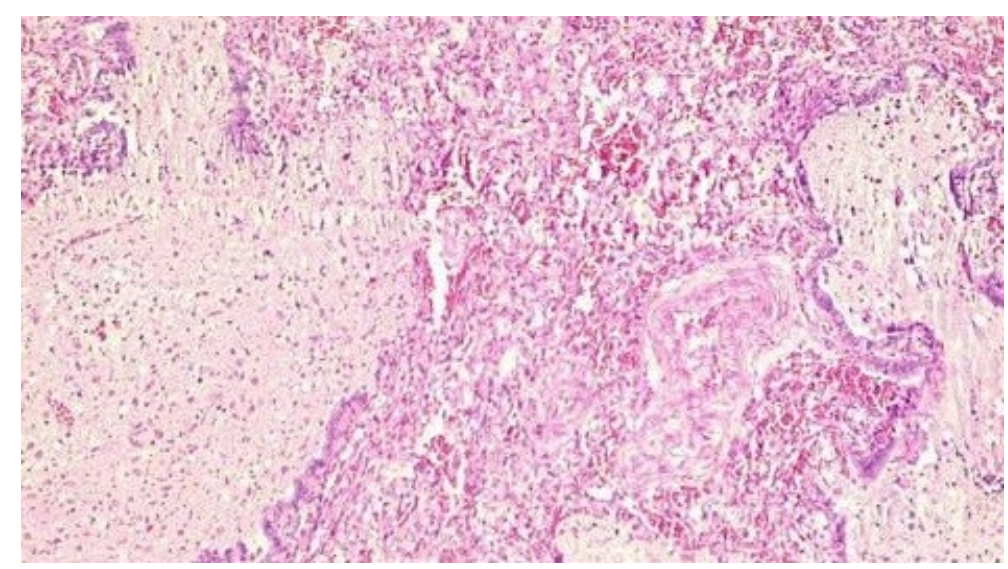

Fig .6. Cysts with mucinous content, lined by cylindrical ciliated epithelium, isolated muscle fibers, vascular structures with thickened walls, collapsed alveoli and hyperemiated vessels.

Hematoxylin-Eosin stain, $10 \mathrm{X}$

At 39 weeks of gestation the male new-born child was delivered by caesarian section. The weight at birth was $3440 \mathrm{~g}$ and the length $50 \mathrm{~cm}$. He was vigorous at birth, breathed spontaneous, without any sign of respiratory or cardiac distress. The Apgar score was 9 at $1 \mathrm{~min}$ and 10 at 5 min. Clinical exam at birth was undistinctive except for the diminished respiratory sounds at the base of the left hemithorax. A chest $\mathrm{x}$-ray was performed and revealed a triangular opacity at the base of the left lung (Fig.2). Blood samples were collected and extensive lab work was carried out. The results were also unremarkable.

Contrast enhanced computer tomography was performed 7 days from birth and revealed a solid mass located inside the left pleura, at the base of the thorax, in close contact with the left lung, measuring grossly 40/35/35 $\mathrm{mm}$, with an arterial vascular supply emerging from the descending aorta and a venous system that drains to the hemiazygos vein (Fig. 3). Based on this findings the diagnostic of extralobar sequestration was set.

The decision was to postpone surgical treatment at least until the age of 6 months. Clinical follow up was carried on monthly bases and the clinical course was uneventful.

At 7 moth of age $7 \mathrm{~kg}$ of weight and $57 \mathrm{~cm}$ height the infant was admitted for scheduled surgical excision of the sequestration.

The child was placed under general anesthesia with oro-tracheal intubation. He was positioned on right lateral decubitus with the left arm in 900 abduction. A five $5 \mathrm{~mm}$ optic port for was placed in 4th intercostal space on the posterior axillary line. Two $3 \mathrm{~mm}$ working ports were placed, one in the 5 th intercostal space $3 \mathrm{~cm}$ posteriorly from the posterior axillary line and one in the 7 th space on the anterior axillary line. The mass was identified at the base of the left lung. It was well-marked, purple, and had no connection with pulmonary parenchyma. The mass had an arterial supply coming from the thoracic aorta and a vein draining in the hemiazygos system. The vessels were covered by the parietal pleura, both were short intimately stick to each other. After difficult and meticulous dissection both vessels were ligated using hemlocks plus additional braid suture and then cut (Fig. 5). The mass was placed in an endobag removed through the anterior axillary line incision enlarge to app. $20 \mathrm{~mm}$. A pleural tube was placed and maintained for 48 hours.

The histopathological examination, showed a modified architecture, presenting cystic spaces of variable dimensions covered with cylindrical/cubic ciliated epithelium, fibrous connective tissue with mucinous content, diffuse and chronic infiltrate, along with collapsed alveoli (Fig. 6). All of this are suggestive for a pulmonary sequestration, associating a nonspecific chronic inflammatory process.

Follow up visits were performed up to 6 months after surgery and revealed an uneventful postoperative course of the case.

\section{Discussions}

Pulmonary sequestration refers to an aberrant formation of segmental lung tissue in the embryonic period that has no connection with the bronchial tree [2]. Of the two types of pulmonary sequestration, the extralobar variant is the less frequent [3]. Most patients with extralobar sequestration are asymptomatic beyond neonatal period. Depending of the size and location of the mass it may produce chronic cough, frequent respiratory infections, compression and/ or functional impairment over nearby structures [5].

Nowadays most of the pulmonary malformations are diagnosed before birth by ultrasound [4, 8]. Antenatal diagnostic is a very useful tool because it can indicate the size, the consistency (solid/mixed lesions), it offers predicting factor for the postnatal evolution of the malformation [8]. In our case, the diagnostic of pulmonary 
malformation was suspected at the routine ultrasound. Fetal MRI gave us a more accurate picture of the lesions, sixe, location, structure, the relation with normal lung tissue. Our decision to carry on with the pregnancy until term was based in these information. However, neither antenatal ultrasound nor the antenatal MRI could offer an exact diagnostic for the mass. They could not differentiate between am intralobar or extralobar lesion. Moreover, the presence of the cystic structures inside the mass was suggestive for CCAM rather than an ELS. So the final diagnostic of ELS was made 1 month after birth by computed tomography. Contrast CT is the best imaging tool for the postnatal assessment of pulmonary malformations and in ELS the pathognomonic finding is the identification of the systemic blood supply [9].

Most of the ELS patients are asymptomatic at birth [10]. When symptomatic, they are usually treated by surgical excision. For asymptomatic patient, there is no consensus over the benefits of the surgical excision of the pulmonary sequestration. Several authors advocated against any form of therapy in children with Asymptomatic ELS, emphasizing that ELS tend to regress spontaneously after the age of 4 years $[5,11,12]$. In our case, the decision of performing surgical excision was based on the relatively large size of the intrathoracic mass and uncertainty of the lesion type. Prenatal MRI revealed cystic structures inside the mass which are suggestive for CCAM. Even though the diagnostic of ELS was clear due to the visualization of the systemic vascular supply, there still is the possibility of a mixt CCAM - Sequestration lesion. Regarding the timing for surgery, we decided to perform the surgical procedure after the age of 6 months in order to avoid an unnecessary stress in a young asymptomatic infant and to have sufficient working space to perform the procedure by minimal invasive means. Other authors reported significantly higher morbidity if surgery is performed in children younger than 3 months [6].

Video-assisted thoracoscopic surgery is effective has low grades of complication and conversion [13]. Even though, demanding from the technical point of view, the surgical excision of the ELS in our case went flawless. The main challenge was to isolate, ligate the vessels and safely cut them. Further on the mass was removed without difficulties through an enlarged incision at one of the ports sites. The benefits of the minimal invasive approach were evident in the postoperative course, less pain, fast mobilization, small incision, better esthetics. As previous reports we found that Video-assisted removal of ELS is a feasible and with clear benefits for the patient but it should be performed only by experienced surgeons because of the potential risk of life-threatening vascular injury [14].

\section{Conclusions}

Prenatal diagnostics is a very useful tool in planning and making appropriate therapeutic decision for patients with pulmonary sequestration. Video-assisted thoracoscopic excision is the optimal treatment option for ELS. However, the procedure is technical demanding and shall be performed only by experienced surgeons with enough experience in minimal invasive surgery.

\section{References}

1. Savic B, Birtel FJ, Tholen W, et al. Lung sequestration: Report of seven cases and review of 540 published cases. Thorax 1979;34:96-101.

2. David VL, Radulescu A, Popoiu MC. Congenital lung malformations - a review. Jurnalul Pediatrului. 2006 July-December; IX(35-36): 46-52

3. Pearson EG, Flake AW. Congenital Bronchopulmonary malformations. in Hocomb III GE, Murphy PJ, Ostile DJ. Ashcaft's Pediatric Surgery sixth edition. London, New York Oxford, Philadelphia, St Louis, Sydney, Toronto; Elsevier 2014:302-313

4. Xu G, Zhou J, Zeng S, Zhang M, Ouyang Z, Zhao Y, Yuan H, Tong L, Yin C, Zhou Q. Prenatal Diagnosis of Fetal Intraabdominal Extralobar Pulmonary Sequestration: A 12-year 3-center Experience in China. Sci Rep. 2019 Jan 30;9(1):943.

5. Yoon HM, Kim EA, Chung SH, Kim SO, Jung AY, Cho YA, Yoon $\mathrm{CH}$, Lee JS. Extralobar pulmonary sequestration in neonates: The natural course and predictive factors associated with spontaneous regression. Eur Radiol. 2017 Jun;27(6):2489-2496.

6. Kestenholz PB, Schneiter D, Hillinger S, Lardinois D, Weder W. Thoracoscopic treatment of pulmonary sequestration. Eur J Cardiothorac Surg. 2006 May;29(5):815-8.

7. Belczak SQ, da Silva IT, Bernardes JC, de Macedo FB, Lucato LL, Rodrigues B, Zeque BS. Pulmonary sequestration and endovascular treatment: a case report. J Vasc Bras. 2019 Jan 10;18:e20180110.

8. Wei Y, Li F. Pulmonary sequestration: A retrospective analysis of 2625 cases in China. Eur J Cardio-thoracic Surg. 2011;

9. Abbey P, Das C, Pangtey G, Seith A, Dutta R, Kumar A. Imaging in bronchopulmonary sequestration. Journal of Medical Imaging and Radiation Oncology. 2009.

10. Annunziata F, Bush A, Borgia Ef, Raimondi F, Montella S, Poeta $\mathrm{M}$, et al. Congenital lung malformations: Unresolved issues and unanswered questions. Frontiers in Pediatrics. 2019.

11. Garcia-Pena P, Lucaya J, Hendry GM, McAndrew PT, Duran C (1998) Spontaneous involution of pulmonary sequestration in children: a report of two cases and review of the literature. Pediatr Radiol 28:266-270

12. Laberge JM, Bratu I, Flageole H (2004) The management of asymptomatic congenital lung malformations. Paediatr Respir Rev 5:S305-312 
13. Tsao K, St Peter SD, Sharp SW, Nair A, Andrews WS, Sharp RJ, Snyder CL, Ostlie DJ, Holcomb GW. Current Application of Thoracoscopy in Children. J Laparoendosc Adv Surg Tech A. 2008 Feb;18(1):131-5

14. Liu C, Pu Q, Ma L, Mei J, Xiao Z, Liao H, Liu L.Video-assisted thoracic surgery for pulmonary sequestration compared with posterolateral thoracotomy. J Thorac Cardiovasc Surg. 2013 Sep;146(3):557-61.

Correspondence to:

\section{Diana Popescu}

Department of Pediatric Surgery and Orthopedics

"Louis Turcanu” Emergency Children's Hospital

2 Dr. Iosif Nemoianu,

300011 Timisoara, Romania

Tel. +4 0785723267

Email: popescudia90@gmail.com 